\title{
A Summary Report on the Model-Based Enterprise Capability Index and Guidebook Workshop
}

Prepared for

Allison Barnard Feeney

Thomas Hedberg, Jr.

National Institute of Standards and Technology

Gaithersburg MD 20899

Prepared by

Joan Pellegrino

Yannick Tamm

Energetics Incorporated

Columbia MD 21046

This publication is available free of charge from: http://dx.doi.org/10.6028/NIST.AMS.100-1

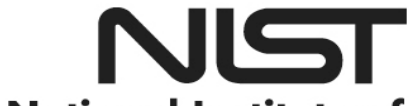

National Institute of Standards and Technology U.S. Department of Commerce 



\section{A Summary Report on the Model-Based Enterprise Capability Index and Guidebook Workshop}

Prepared for Allison Barnard Feeney Thomas Hedberg, Jr. Systems Integration Division Engineering Laboratory

Prepared by Joan Pellegrino Yannick Tamm Energetics Incorporated

This publication is available free of charge from: http://dx.doi.org/10.6028/NIST.AMS.100-1

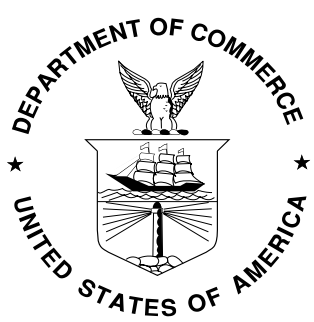

U.S. Department of Commerce

Penny Pritzker, Secretary 


\section{DISCLAIMER}

This report was prepared as an account of work co-sponsored by National Institute of Standards and Technology (NIST). The views and opinions expressed herein do not necessarily state or reflect those of NIST. Certain commercial entities, equipment, or materials may be identified in this document to illustrate a point or concept adequately. Such identification is not intended to imply recommendation or endorsement by the NIST, nor is it intended to imply that the entities, materials, or equipment are necessarily the best available for the purpose.

National Institute of Standards and Technology Advanced Manufacturing Series 100-1

Natl. Inst. Stand. Technol. AMS 100-1, 27 pages (June 2016)

This publication is available free of charge from: http://dx.doi.org/10.6028/NIST.AMS.100-1 


\section{Table of Contents}

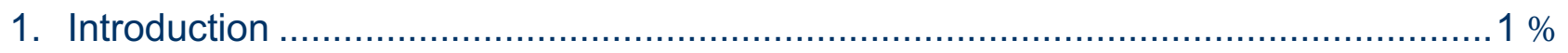

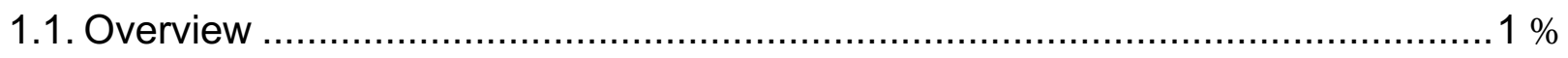

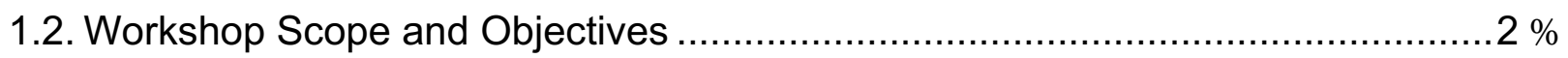

2. Review of Capabilities Index and Assessment ..................................................... $4 \%$

2.1. Capability Index Suitability and Gaps ........................................................ $\%$

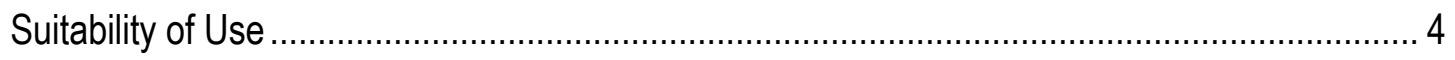

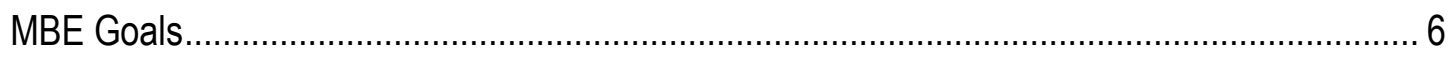

Current Experience with the MBE Capabilities Index ...................................................... 6

2.2. MBE Capabilities Index Applications .........................................................

Internal Uses for the MBE Capabilities Index ................................................................... 7

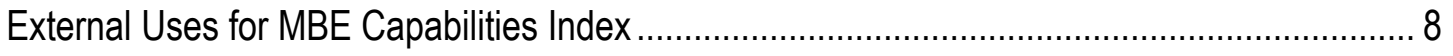

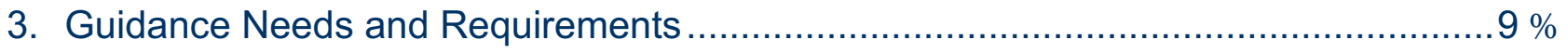

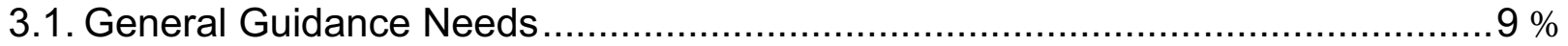

3.2. Guidance Needs Specific to Design, Engineering, and Planning......................12\%

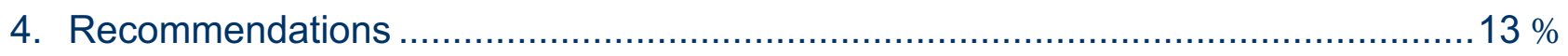

4.1. Recommendations for Governance, Format, and Outreach ..........................13\%

4.2. Recommendations for Guidebook Content .................................................15\%

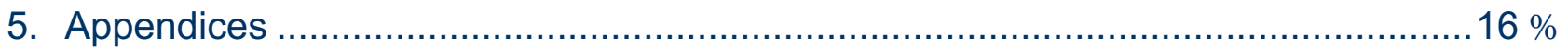
A. Workshop Agenda
$17 \%$
B. Participant List
$18 \%$
C. Acronyms. $19 \%$
D. References $20 \%$

\section{Notes}

Nomenclature and acronyms are not defined in the body of the text. Refer to Appendix 5.C for a list of all nomenclature and acronyms. 



\section{Introduction}

\subsection{Overview}

A Model-Based Enterprise (MBE) is "an integrated and collaborative environment, founded on 3D product definition shared across the enterprise, enabling rapid, seamless, and affordable deployment of products from concept to disposal," (Model Based Enterprise, 2014). When an organization operates under an MBE, their divisions, branches, etc. operate under a single source of truth: the product model. The model could be an annotated computer-aided design (CAD) model or a model-based systems model defined in SysML. Regardless of the model's form, an organization operating under these conditions could eliminate the inefficiencies and opportunities for errors of recreating domainspecific or "silo-ed" drawings. A study showed that a MBE approach results potentially in a $75 \%$ average reduction in cycle-time over a drawing-based approach (Hedberg Jr, Lubell, Fischer, Maggiano, \& Barnard Feeney, 2016). In addition to bringing products to market quicker and cheaper, an additional benefit of MBE is the ability to potentially reduce the cost of supporting and maintaining the product throughout its life (Model Based Enterprise, 2014)

The National Institute of Standards and Technology (NIST) held a "Model-Based Enterprise Summit" from April 12 - 14, 2016. The goal of the summit was to identify challenges, research, implementation issues, and lessons learned in manufacturing and quality assurance where a digital threedimensional (3D) model of the product serves as the authoritative information source for all activities in the product's lifecycle. This 3D model is considered a model-based definition (MBD) and acts as

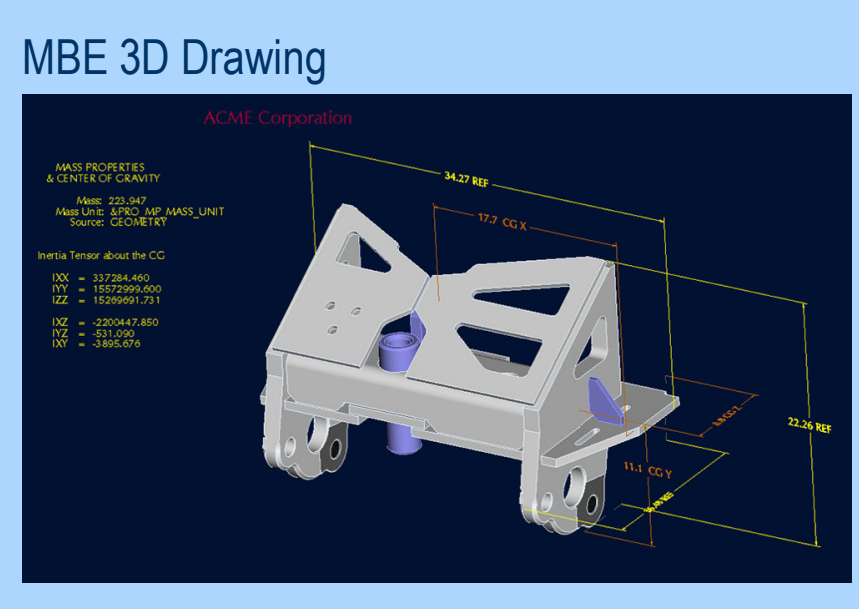

Example of a model-based definition acting as the authoritative information source for all activities in the product's lifecycle. (Model Based Enterprise, 2014) 
a "digital thread" 1 " of sorts to weave and link all the phases of the product lifecycle together. The U.S. Department of Defense (DoD) and NIST developed a tool to help organizations assess whether they are ready for an MBE or smart manufacturing platform. The tool was named: "MBE Capability Index Assessment Tool." As part of the summit, NIST was also interested in collecting input specific to the MBE Capability Index Assessment Tool and the consideration for developing a guidebook for the tool.

\subsection{Workshop Scope and Objectives}

NIST hosted the Measurement Science for Model-Based-Enterprise Capabilities Workshop on April 15, 2016 to better assess the MBE Capability Index and gather input for a potential guidebook. The workshop brought together experts from industry, government, and academia to identify the barriers, needs, and recommendations for developing a MBE Capability Index Assessment Tool guidebook. The purpose of the guidebook is to help an organization navigate and effectively use the MBE Assessment tool. This includes assessing MBE capabilities, interpreting assessment results, determining actions the organization could take, and outlining a minimum set of requirements to qualify as a model-based enterprise.

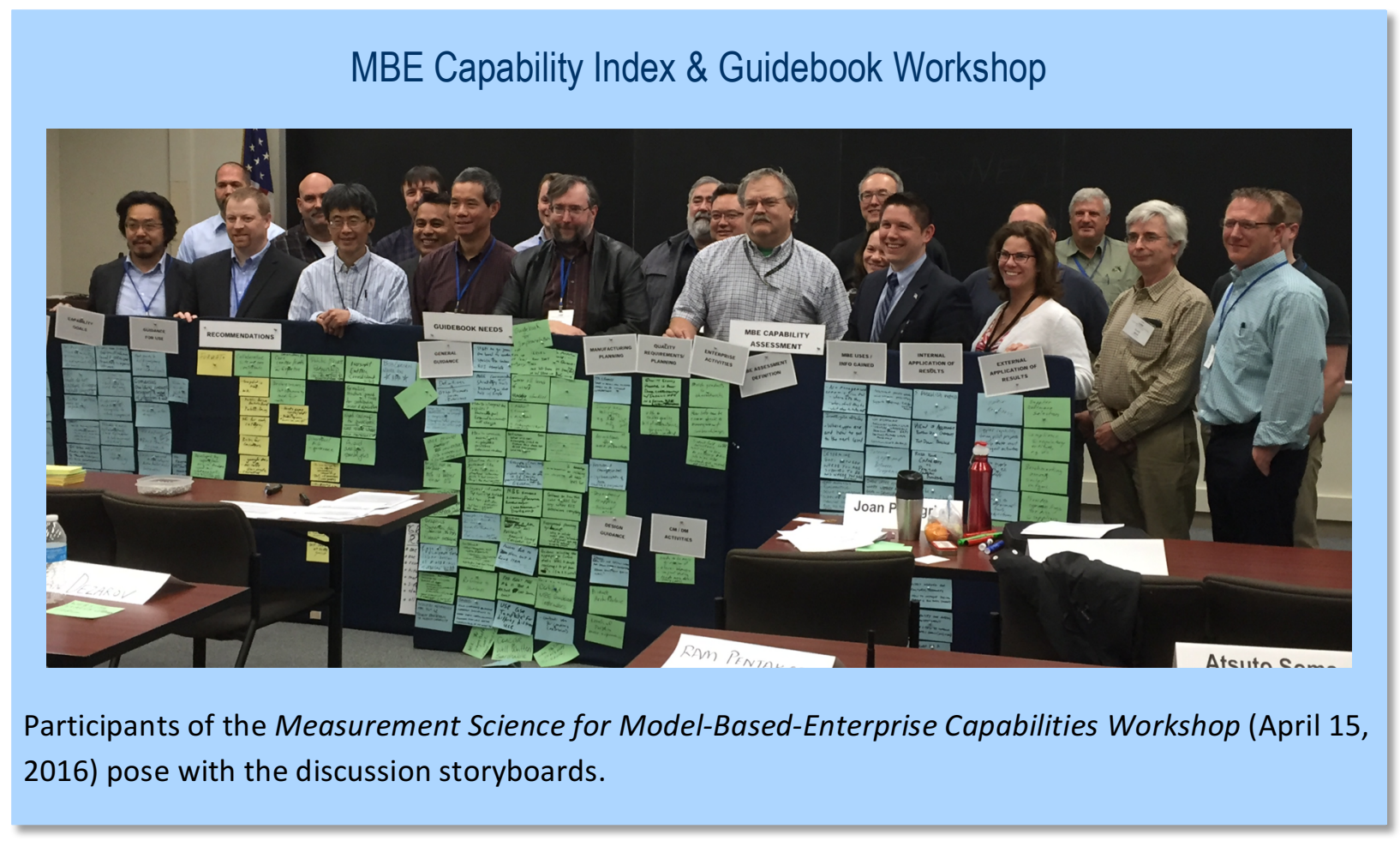

\footnotetext{
${ }^{1}$ The digital thread is a concept for linking all phase of the product lifecycle together using 3D model-based definitions. In a manufacturing context, all of the machines would use the same set of digital instructions, errors would be caught automatically, ensuring the end result matches the intended design. For more information on the digital thread visit: https://youtu.be/iGtM8VGLn5M.
}

Model-Based Enterprise Capability Index and Guidebook Workshop Summary Report 
Participants of the workshop convened on NIST's Gaithersburg campus to participate in a facilitated discussion. The discussions were organized into four sessions:

- Capability Index

- MBE Capabilities Assessment

- Guidebook Needs

- Recommendations

The first two sessions primarily focused on evaluating the MBE Capability Index, itself, while the latter two sessions addressed needs and recommendations for developing a guidebook for the index.

Participants were asked to write their ideas for each session on cards, which were then pinned to a storyboard at the front of the room. Similar ideas were categorized under appropriate topics to keep the discussion outcomes organized and transparent. The results of this exercise for all sessions are captured in this report.

The MBE Capability Index tool is available for free download at:

https://github.com/usnistgov/DT4SM/tree/master/MBE-Capabilities-Assessment 


\section{Review of Capabilities Index and Assessment}

The workshop discussions began with a brainstorming session to get participants to think critically about the MBE Capability Index. Each participant was given an opportunity to share their ideas and engage fully in the discussion. The outcomes are summarized in the following sections.

\subsection{Capability Index Suitability and Gaps}

Subject-matter experts from the DoD and NIST brainstormed on focus areas prior to the workshop. The "Capability Index Suitability and Gaps" session included four guiding topic questions from the brainstorming:

1. Does the Capability Index meet your needs for measuring and assessing MBE capabilities and gaps in facilities?

2. Are the index capability goals appropriate, based on your experience?

3. Do you have suggestions for improving or revising the goals and baseline?

4. Has anyone developed their own assessment method using this index?

\section{Suitability of Use}

Discussions focused on the suitability and usability of the tool and mitigating factors such as clarity, complexity, terminology, definitions, etc. The tool was noted as suitable by the workshop participants for the following uses:

- Baselining current practices in MBE, i.e., a reference that an organization would built upon.

- Providing a consistent baseline that an organization would use to assess how capabilities have improved over a period of time.

- Starting point for focused discussions on MBE to help identify the current state of MBE in an organization.

While deemed suitable for use in some ways, and that the latest version is an improvement, a number of issues and challenges were identified. The main points that arose include the need for better defining terms; understanding, setting, and interpreting the different capability levels accurately; navigating the usability of the tool, given its complexity; and gaps in the existing framework of the tool. Table 2-2 summarizes the discussions and some useful improvements. 
Table 2-1. MBE Capability Index Suitability and Gaps

\begin{tabular}{|c|c|c|c|}
\hline MBE Levels & $\begin{array}{l}\text { Definitions and } \\
\text { Terminology }\end{array}$ & Complexity & Gaps \\
\hline $\begin{array}{l}\text { Current index is } \\
\text { high level, needs } \\
\text { more detailed } \\
\text { definitions and } \\
\text { descriptions, } \\
\text { explanations and } \\
\text { interpretation } \\
\text { Logistics and } \\
\text { change } \\
\text { management } \\
\text { aspects should be } \\
\text { included in levels } \\
\text { Tool does not } \\
\text { account for length } \\
\text { of time required to } \\
\text { be at a given level } \\
\text { Levels are helpful, } \\
\text { but expert help is } \\
\text { needed to } \\
\text { understand how to } \\
\text { get to future state } \\
\text { How to get to future } \\
\text { state or next level is } \\
\text { unclear }\end{array}$ & $\begin{array}{l}\text { - Specific details are } \\
\text { lacking (too } \\
\text { ambiguous) } \\
\text { Hard to describe the } \\
\text { tool and its uses (e.g., } \\
\text { for training staff) } \\
\text { - Not enough detail is } \\
\text { provided to identify } \\
\text { gaps; more detail is } \\
\text { required in boxes } \\
\text { Tool is not self- } \\
\text { explanatory; lacks } \\
\text { overall definitions } \\
\text { Product definition } \\
\text { standard is incomplete } \\
\text { and ambiguous } \\
\text { Lacks clarity - difficult } \\
\text { to gain consensus on } \\
\text { the outcomes }\end{array}$ & $\begin{array}{l}\text { Extensive text is } \\
\text { hard to follow } \\
\text { - Too complex } \\
\text { Too complicated } \\
\text { for a simple } \\
\text { capability } \\
\text { assessment } \\
\text { Useful, but really } \\
\text { need SMEs to do } \\
\text { an assessment (no } \\
\text { experts on staff) }\end{array}$ & $\begin{array}{l}\text { - } \quad \text { No option for N/A } \\
\text { Geared toward a } \\
\text { specific type of } \\
\text { company (suits } \\
\text { large } \\
\text { manufacturers } \\
\text { rather than small } \\
\text { shops/R\&D } \\
\text { companies) } \\
\text { - Lacks } \\
\text { assessment for } \\
\text { product } \\
\text { architecture } \\
\text { (system } \\
\text { engineering) } \\
\text { Does not address } \\
\text { customized } \\
\text { applications, like } \\
\text { ship repair } \\
\text { Ability to cover } \\
\text { multi-programs, } \\
\text { new designs } \\
\text { Dynamic options, } \\
\text { e.g., has to be a } \\
\text { living document } \\
\text { as technology } \\
\text { changes }\end{array}$ \\
\hline \multicolumn{4}{|c|}{ Suggested Improvements } \\
\hline \multicolumn{4}{|c|}{$\begin{array}{l}\text { - } \text { Detailed questions to make steps clearer } \\
\text { - Survey questions to interview people (detail lacking) } \\
\text { - Meta model (to support well-defined relationships) } \\
\text { - Use fewer levels to reduce complexity } \\
\text { - } \text { Definitions, instructions, and details to make it easier to use; you have to be knowledgeable to self- } \\
\text { - Explanation/interpretation for scores - score can have shock value } \\
\text { - More graphics and data visualization - especially when incorporating supply chain aspects }\end{array}$} \\
\hline
\end{tabular}




\section{MBE Goals}

The goals discussion focused on the appropriateness of the goals as currently defined in the tool. Goals were deemed to be generally appropriate, but not customizable to individual situations. Some of the key issues and improvements identified are shown in Table 2-2.

Table 2-2. Suitability of MBE Capability Index Goals

\begin{tabular}{|c|c|}
\hline Assessment of Performance/Economics & Customization of Goals \\
\hline $\begin{array}{l}\text { - } \quad \text { Potential to apply goals to ROI } \\
\text { - } \quad \text { Gse results / goals to develop ROI metrics } \\
\text { performance } \\
\text { - Could identify business and operational } \\
\text { drivers, and connect to goals, e.g.: } \\
\circ \quad \text { Standardizing processes } \\
\circ \quad \text { Aligning with value chain } \\
\circ \quad \text { Assessing agility and adaptability to } \\
\text { change } \\
\text { Data reuse }\end{array}$ & $\begin{array}{l}\text { - Tool does not allow the assessor to tailor goals to } \\
\text { the organization's situation } \\
\text { - Actual goals are very industry specific and are } \\
\text { dynamic; this could change as more companies } \\
\text { adopt MBE } \\
\text { - Goals should be designed to vary by supplier tier } \\
\text { - Goals are suitable, but must be taken granularly } \\
\text { and considered within the specific business } \\
\text { environment } \\
\text { - Goals currently do not capture enterprise needs or } \\
\text { downstream re-use } \\
\text { Work collaboratively with key suppliers to take } \\
\text { assessment }\end{array}$ \\
\hline \multicolumn{2}{|c|}{ Suggested Improvements } \\
\hline \multicolumn{2}{|c|}{$\begin{array}{l}\text { - Current commercially available tools cannot achieve level 6; would be good to use this to improve } \\
\text { software } \\
\text { - Write goals more as a capability } \\
\text { - Goals are organization dependent, not definitive; a guide is needed for how a company should set } \\
\text { their MBE goals } \\
\text { - Could use another level to make comparisons between companies or facilities (although not the } \\
\text { intended use) } \\
\text { - Better ability for customization to specific facilities or business models }\end{array}$} \\
\hline
\end{tabular}

\section{Current Experience with the MBE Capabilities Index}

A number of organizations indicated they had used the tool and developed a methodology in their facility. Successful use cases included:

- Action Engineering - used the tool to develop an action plan for MBE; developed a tailored method

- Honeywell - used the tool in its current state; created a management level chart to convey levels and issues

- Mitutoyo America Corporation - As a supplier, used the tool in its current state

- Sandia National Laboratory - Used for design, as internal document (Concept of Operations), and to generate roadmap and baseline; added product architecture

- MBC360 LLC - Added detail and descriptions first to allow scoring by category

Cases where issues arose in use or the tool proved insufficient included:

- The U.S. Navy Shipyards - found the tool was not detailed enough, and rows would need different dimensions; this facility's environment was too radically different to utilize the tool 


\subsection{MBE Capabilities Index Applications}

The applications discussion included the following topic questions:

1. How will you use a completed MBE assessment?

2. What knowledge do you expect to gain from a completed MBE assessment?

3. How will you apply the results of a completed assessment to help your facility achieve MBE?

4. Will you apply the results beyond internal use, for example, to customers and supply chains?

Results of the discussion are presented in the following sections.

\section{Internal Uses for the MBE Capabilities Index}

A number of useful applications were identified for the MBE Capabilities Index. In addition to bringing organizations up to MBE requirements, the tool could potentially be used to justify investments in MBE, communicate $\mathrm{MBE}$ considerations to management, enable organizations to measure progress toward MBE goals, and to assess the MBE capabilities of suppliers. Some improvements are needed to enable the more wide-ranging applications. Table 2-3 summarizes the highlights of discussions.

Table 2-3. Applications of MBE Capabilities Index Results

\section{MBE Uses and Internal Application of Results}

- Communicating to management on MBE actions, goals, and investment requests

- Identifying, justifying, and legitimizing areas for investment

- Supporting documentation for ROI for reaching next level (not currently in tool)

- Educating others on what MBE is and where we need to be; educating value-stream subject matter experts and management via the assessment process

- Better understanding MBE scope progression

- Creation of unified vision for MBE initiatives

- Build consensus of MBE goals

- Inter-facility communication on all aspects of MBE

- Documentation of processes, tools, common methods, media training and facility

- Prioritization of tasks for MBE

- Establishment of metrics for MBE and analysis of progress toward goals

- Rating facility capability versus practice

- Consensus and team building on MBE aspects; create impetus and understanding of need for cultural changes

- Improving digital thread of big data development plan for facility

들 - As a driver and record for measuring progress

- Documentation of current state

- Baseline process for MBE; also as a baseline to develop ROI metrics

- As a dual view of MBE assessment: bottom up - capabilities; top down - practices

- More complete understanding of internal system capabilities

- Framework for a benchmark used in the acquisition of a new CAD/PDM/PLM system 
MBE Uses and Internal Application of Results

- Roadmapping - how to reach to next MBE level (i.e., reach the desired level, given the baseline or current state)

- Identifying/ investigating obstacles to reaching the next level (social, technological, etc.)

- Plan and strategy (goals and objectives) for reaching next level

- Identifying needs, resources, and actions/next steps for MBE implementation

- Understanding the right progression of steps

- Educating decision makers on plan/steps to reach the next level

- Analysis of gaps between current and desired states

- Facility-level

- Enterprise-level

- Between programs

- Comparison of roadmap goals and plan for achieving goals (where gaps exist)

\section{External Uses for MBE Capabilities Index}

A few external uses were identified for the MBE Capabilities Assessment tool, primarily for the assessment of suppliers. These include:

- Supplier and partner readiness for MBE

- Working directly with partners, going through the assessment and gaining agreement on levels and objectives

- Using results for downstream partner alignment and assessment

- Identifying where and how to improve the external supply chain

- Identification of supplier capabilities during MBE pilot projects to optimize project activities

- Benchmarking among similar manufacturers / suppliers

- Assessing the ability of supply chain to accept 3D models

- Supplier software selection

- Communications - providing common terminology for discussions with suppliers; data exchange could be an issue.

- Benchmarking among similar manufacturers / suppliers, or outside organizations

- Compliance with regulatory entities (e.g., UL, FAA)

- Assessment to meet sponsor date or other requirements (e.g., government)

- Sustainment, e.g., government purchase of spare parts, to sustain the product as far as possible 


\section{Guidance Needs and Requirements}

The third session, titled "Guidance Needs and Requirements" encouraged a deep-dive to collect input for developing a guidebook for the MBE Capability Index. The facilitator introduced this session with three new guiding topic questions:

1. What kind of general guidance do you think will be most useful to you?

2. What further guidance is needed to enable effective use of the capability index?

3. Can you identify needed guidance requirements specific to Design, CM/DM Activities, Manufacturing Planning, Quality Requirements/Planning, and Enterprise Activities?

Results of the discussion are presented in the following sections.

\subsection{General Guidance Needs}

Additional guidance is needed to effectively implement the MBE Capability Index as an assessment tool. A number of key areas were identified where guidance would be especially valuable. These include definitions, use cases and examples of best practices, how to best implement the assessment process, explanation and interpretation of levels, and how to effectively connect the assessment to MBE investments. A key consideration is how to tailor and apply the tool to various types of organizations. Highlights of discussions in each of these areas are provided in Table 3-1Table 2-3.

Table 3-1. Suggested Inputs to the MBE Capabilities Assessment Guidebook

\begin{tabular}{|c|c|c|}
\hline & \multicolumn{2}{|c|}{ Guidance Needs } \\
\hline 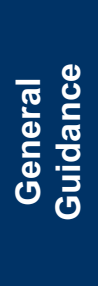 & $\begin{array}{l}\text { - } \quad \text { Concise and well-written } \\
\text { - } \quad \text { Searchable } \\
\text { - } \quad \text { exer-friendly, understandable by non- } \\
\text { - } \quad \text { Checklist and other templates } \\
\text { - } \quad \text { Publish a new index (quickly, not } \\
\quad \text { perfect) }\end{array}$ & $\begin{array}{l}\text { - } \quad \text { Rules and controls } \\
\text { - } \quad \text { Ease of use } \\
\text { - } \quad \text { Relevant information is provided } \\
\text { - } \quad \text { Acknowledge PMl levels } \\
\text { - } \quad \text { Work toward } 80 \% \text { completion of the } \\
\quad \text { guidebook (it need not be perfect on first go) }\end{array}$ \\
\hline
\end{tabular}




\begin{tabular}{|c|c|c|}
\hline \multirow[b]{2}{*}{ 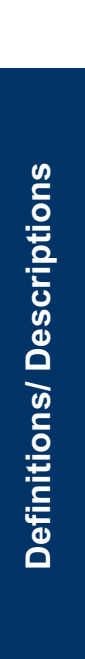 } & \multicolumn{2}{|c|}{ Guidance Needs } \\
\hline & $\begin{array}{l}\text { Definitive explanation of terms and } \\
\text { processes } \\
\text { - Survey to aid in answering questions } \\
\text { - } \quad \text { Interviews (e.g., day in the of life of a } \\
\text { part) } \\
\text { - Unambiguous directions / instructions } \\
\text { for use } \\
\text { Well-described levels with constraints, } \\
\text { attributes, definitions, and goals } \\
\text { Description of the lifecycle phases of } \\
\text { MBE: } \\
\text { Assessment } \\
\text { Analysis of assessment } \\
\text { Roadmap for implementation } \\
\circ \text { Evaluation of changes and impacts }\end{array}$ & $\begin{array}{l}\text { - } \quad \text { Well-defined meta model XMI (e.g., OMG) } \\
\text { - } \quad \text { Definition/description of MBE } 6 \text { consensus } \\
\text { assessment non-purpose - what the } \\
\text { as its limitations } \\
\text { - } \quad \text { Expandended to accomplish, as well } \\
\text { - } \quad \text { Better descriptions of levels and goals } \\
\text { - } \quad \text { ayered information and details } \\
\circ \quad \text { Top layer = high level bullet points } \\
\circ \quad 2^{\text {nd }} \text { layer = definitions and explanations } \\
\circ \quad 3^{\text {rd }} \text { layer = examples } \\
\circ \quad 4^{\text {th }} \text { layer }=\text { to be defined (e.g., graphics) }\end{array}$ \\
\hline 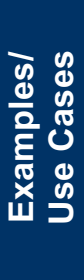 & $\begin{array}{ll}\text { - } & \text { Representative assessment results } \\
\text { (but ensure this does not drive } \\
\text { outcomes) } \\
\text { - } \quad \text { Best practices } \\
\text { - } \quad \text { Use cases } \\
\text { Recommended practice for each } \\
\text { category in the tool, within the scope }\end{array}$ & $\begin{array}{l}\text { - } \quad \text { Specific examples for each individual field } \\
\text { - } \quad \text { Examples of technology for reaching each } \\
\text { level to inform the novice } \\
\text { - Use case templates for differing downstream } \\
\text { uses }\end{array}$ \\
\hline 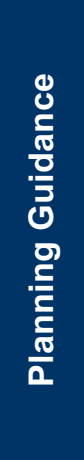 & $\begin{array}{l}\text { How to design assessment process } \\
\text { Scope - identify what is in/out of } \\
\text { scope } \\
\circ \text { Guide to help companies set } \\
\text { individual goals, determine level } \\
\text { appropriate to business model } \\
\circ \text { Guide for different industry types } \\
\circ \text { How to create architectural map with } \\
\text { data elements, consumption } \\
\text { framework } \\
\circ \text { Typical stakeholder list (entire } \\
\text { enterprise) }\end{array}$ & 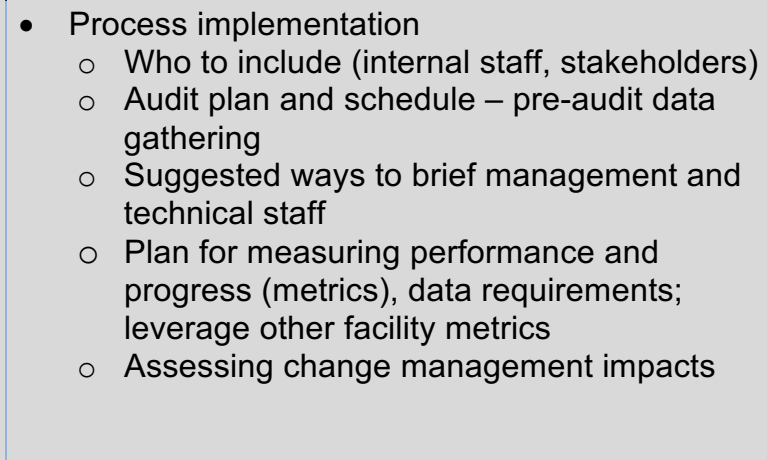 \\
\hline
\end{tabular}

- Easy way to assess your baseline to incremental assessments along the way

- How to proceed after gaps are identified, including prioritization of next steps

- Next step guidance: steps to go from one level to another; identifying gaps, then creating milestones, project plans, tasks; how to build an actionable plan based on assessment outcomes

- Examples of how to move up to the next level for each category

- Guidance for selecting the appropriate future state level

- Sample roadmaps and expected challenges to get from level to level (e.g., from 1.5 to 4.5 overall)
- Guidance on how to interpret the results (e.g., work toward reasonable goal)

- Funding requirements, ROI templates

- Guidance on how MBE/results links to ROI

- Add a level migration that includes:

- Replacing 2D static drawings with 3D interactive viewable documents (aka 3D PRC-PDF) used for human consumption

- Emphasize quality as important as upstream processes

- Add level migration that include capabilities enabling quality functions:

- Metrology standards (e.g., QIF)

- Use of BoC (Bill of Characteristics)

- Computer readable

- Human readable 


\section{Guidance Needs}

- MBE communication strategy at all levels

- How to convince executives, employees, partners, software vendors that MBE is worthwhile investment

- Describes technologies that help with implementation

- Structure tool and guidebook similar to TurboTax $®$ - have a structured "interview" guide to lead companies through the tool and answer questions
- Robust messaging for MBE

- Consensus building amongst designers and implementers of intentions and use of tool

- Dynamic and interactive document

- Incorporate web links, 3D PDFs

- Use WiKi - identify pages that need work (could be crowd-sourced)

- $\quad$ Live interactions - WiKi type forum

- Identify potential technical issues for software vendors, e.g., data conversion of semantic PMI

- Training on how to use the guidebook; certified MBE guidebook instructors

- Contact information for questions (and a mechanism for such assistance)
- Help in identifying the appropriate and qualified facilitators or experts

- Workshops among different disciplines to share needs, concerns, understand big picture
- List of references (standards) that the guidebook is referring

- How standards can be applied to help with advancing MBE capabilities
- Industry references, such as MBE, PLM, etc.

- Cyber-physical security 


\subsection{Guidance Needs Specific to Design, Engineering, and Planning}

A number of guidance requirements specific to Design, Change Management (CM) and Data Management (DM) Activities, Manufacturing Planning, Quality Requirements and Planning, and Enterprise Activities were identified. These results can be seen in Table 3-2, organized by function.

Table 3-2. MBE Guidebook Needs for Design, Engineering, and Planning

\begin{tabular}{|c|c|c|c|c|}
\hline $\begin{array}{l}\text { Manufacturing } \\
\text { Planning }\end{array}$ & $\begin{array}{c}\text { Quality } \\
\text { Requirements / } \\
\text { Planning }\end{array}$ & $\begin{array}{l}\text { Enterprise } \\
\text { Activities }\end{array}$ & $\begin{array}{l}\text { CM / DM } \\
\text { Activities }\end{array}$ & $\begin{array}{l}\text { Design } \\
\text { Guidance }\end{array}$ \\
\hline $\begin{array}{l}\text { Manufacturing and } \\
\text { Quality - share in } \\
\text { detail how to design } \\
\text { models to be } \\
\text { machine-interpretable } \\
\text { - Incorporate new } \\
\text { technology, e.g., } \\
\text { additive } \\
\text { manufacturing, into } \\
\text { manufacturing design } \\
\text { Revision and change } \\
\text { control guidance } \\
\text { Synchronization of } \\
\text { data } \\
\text { Tracking and } \\
\text { progressing toward } \\
\text { levels } \\
\text { Dependency mapping } \\
\text { between areas }\end{array}$ & 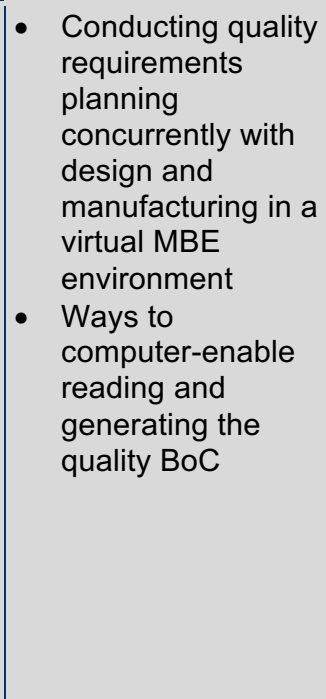 & $\begin{array}{l}\text { - } \text { Matching products } \\
\text { to characteristics } \\
\text { cow to } \\
\text { communicate } \\
\text { information back } \\
\text { to management } \\
\text { dashboards/ } \\
\text { maps } \\
\text { Product field } \\
\text { LoTAR } \\
\text { surveillance to } \\
\text { meet regulations } \\
\text { (how to } \\
\text { incorporate } \\
\text { information in a } \\
\text { MBE) } \\
\text { Feedback on as } \\
\text { is, as used, end of } \\
\text { life, etc. }\end{array}$ & \begin{tabular}{|l} 
- \\
moeds to be \\
granular; \\
more detail \\
for this \\
category \\
- How to \\
assess \\
changes, \\
conduct \\
impact \\
studies \\
Change \\
control \\
aspects
\end{tabular} & 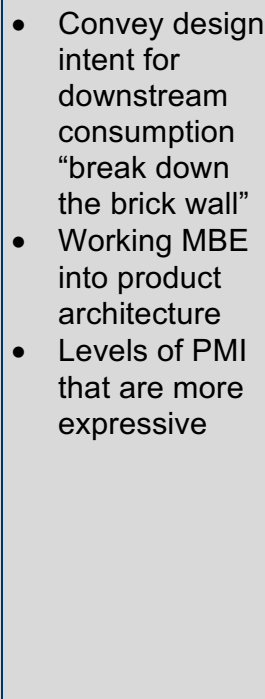 \\
\hline
\end{tabular}




\section{Recommendations}

The guiding question for this session focused on pulling a final set of recommendations for developing an effective guidebook:

1. What overall recommendations do you have for developing a useful, effective Guidebook for assessment of MBE capabilities?

Recommendations were generated in two basic categories: 1) overall governance, format, and outreach for the guidebook, and 2) guidebook content. These are described in the following sections.

\subsection{Recommendations for Governance, Format, and Outreach}

Five overall recommendations were identified, as shown in Tables 4.1-4.5. These illustrate the importance of collaboration among stakeholders in developing the guidebook; the need for oversight and governance in general; and the need for improvements to create an effective, customizable, and usable MBE Capabilities Assessment tool.

Table 4-1. MBE Guidebook Recommendation \#1

\begin{tabular}{|l|l|l|}
\hline \multicolumn{3}{|c|}{ Recommendation \#1: Develop a collaborative website connected to a core } \\
information center and subject matter experts.
\end{tabular}

Table 4-2. MBE Guidebook Recommendation \#2

\section{Recommendation \#2: Organize a discussion working group with governance.}

\section{Structure}

- Public forum with rules on final consensus/ censorship

- Moderated group who says yes/no

- Governing Board provides weight to opinions

- Includes 4-5 basic concepts

- Self-sustaining (at some point)

\section{Process for Consensus}

- Define metric for consensus (e.g., 1,000 people?)

- Popular vote-based (not rigorous consensus)

- Send to Governing Board for final decision

- Make sure no conflicts are present 
Table 4-3. MBE Guidebook Recommendation \#3

\section{Recommendation \#3: Develop guidebook with inputs from original developers, using an} interactive TurboTax®-like format.

\section{Structure}

\section{Resources}

- In the public domain

- Build guidebook similar to TurboTax $®$ user interface and guidance

- Include apps

- $\quad$ NIST to develop governance policy

- $\quad$ NIST to give weight for adoption

- Initial draft in one year

- Information from original developers

- Input from more SMEs (e.g., quality) - plus core SMEs for each domain

- Supplement with working groups

- Aggressively pursue information

- Find a champion/shepherd

- Elevate to authoritative document

Table 4-4. MBE Guidebook Recommendation \#4

\section{Recommendation \#4: Establish an oversight entity.}

\section{Structure}

- Formalize structure/ground rules for contributing content and adjudicating

- Develop a roadmap for the guidebook

- Create a release schedule, as well as an update and maintenance schedule

- Avoid analysis paralysis - work toward "a minimally viable product"

Table 4-5. MBE Guidebook Recommendation \#5

\section{Recommendation \#5: Develop a multi-media communications and outreach plan.}

\section{Outreach Methods}

- Connect/raise awareness at conferences, trade shows, through professional societies, and via web presence

- YouTube ${ }^{\mathrm{TM}}$ videos

- Interviews with industry

- Manufacturing minute podcast

- Messaging in all media

- Broadly disseminated

- $\mathrm{MBE}$ collaborative website (needs a sponsor) 


\subsection{Recommendations for Guidebook Content}

Table 4-6 summarizes the recommendations that relate to guidebook content. These combine many of the ideas expressed throughout the prior working sessions, but are not all-inclusive.

Table 4-6. Additional MBE Guidebook Recommendations from Previous Sessions

\section{Recommendation}

1. More detail and better definition of requirements

2. Leverage examples, case studies and infographics

3. Simplify Index

4. Guidance to tailor tool to different types of organizations

5. Instructions for next steps and interpreting results

6. Communications guide

7. Guide should include additional resources references and standards

8. Well defined meta model with well-defined relationships

\section{Details}

- Better define requirements, terms, and levels in the tool

- Best practice examples

- Recommended practice for each category in the tool

- Use case templates for differing downstream uses

- Recommend using fewer levels in the tool

- Have guide to help company set individual goals

- Guidance for determining the appropriate level for a given business model

- How to interpret the results and build an actionable plan from the assessment

- Include MBE community strategy at all levels e.g., management, staff, etc.

- List of references

- How standards can be applied to help advancing MBE capabilities

- Well-described level with constraints attributes, definitions, goals, etc.

- Meta model XMI 


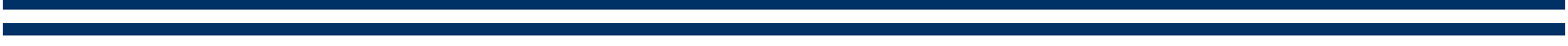

\section{Appendices}




\title{
A. Workshop Agenda
}

\author{
MBE Summit \\ MBE Capability Index \& Guidebook Workshop \\ NIST, Gaithersburg, MD
}

Friday, April 15, 2016

\begin{tabular}{|c|c|c|}
\hline Time & Topic & Speaker(s) \\
\hline \multirow[t]{2}{*}{$0830-0840$} & Welcome and Overview & $\begin{array}{l}\text { Allison Barnard Feeney and } \\
\text { Tom Hedberg, NIST }\end{array}$ \\
\hline & \multicolumn{2}{|l|}{ Facilitated Sessions } \\
\hline 0840-0940 & $\begin{array}{l}\text { Capability Index } \\
\text { Does the Capability Index meet your needs for } \\
\text { measuring and assessing MBE capabilities and gaps in } \\
\text { facilities? } \\
\text { - Are the index capability goals appropriate, based on } \\
\text { your experience? Do you have suggestions for } \\
\text { improving or revising the goals and baseline? } \\
\text { - Has anyone developed their own assessment method } \\
\text { using this index? } \\
\text { What further guidance is needed to enable effective use } \\
\text { of the capability index? }\end{array}$ & $\begin{array}{l}\text { Joan Pellegrino and } \\
\text { Yannick Tamm, } \\
\text { Energetics Incorporated } \\
\text { (Facilitators) }\end{array}$ \\
\hline 0940-1040 & $\begin{array}{l}\text { MBE Capabilities Assessment } \\
\text { - How would you define/describe what an assessment is? } \\
\text { - How will you use a completed MBE assessment? } \\
\text { - } \text { completed MBE assessment? } \\
\text { - How will you apply the results of a completed } \\
\text { assessment to help your facility achieve MBE? } \\
\text { - Will you apply the results beyond internal use, for } \\
\text { example, to customers and supply chains? }\end{array}$ & \\
\hline 10401050 & \multicolumn{2}{|l|}{ Break } \\
\hline $1050-1150$ & $\begin{array}{l}\text { Guidebook Needs } \\
\text { - What kind of general guidance do you think will be } \\
\text { most useful to you? } \\
\text { Can you identify needed guidance requirements specific } \\
\text { to Design, CM/DM Activities, Manufacturing Planning, } \\
\text { Quality Requirements/Planning, and Enterprise } \\
\text { Activities? }\end{array}$ & \\
\hline $1150-1220$ & $\begin{array}{l}\text { Recommendations } \\
\text { - What overall recommendations do you have for } \\
\text { developing a useful, effective Guidebook for } \\
\text { assessment of MBE capabilities? }\end{array}$ & \\
\hline $1220-1230$ & Next Steps and Adjourn & \\
\hline
\end{tabular}




\section{B. Participant List}

\begin{tabular}{|l|l|}
\hline Name & Affiliation \\
\hline Allison Barnard Feeney & NIST \\
\hline Frank Bilek & Pratt \& Whitney \\
\hline Curtis Brown & Honeywell FM\&T \\
\hline Rush Carter & UTRS/AMRDEC \\
\hline Mark Deisbink & Newport News Shipbuilding \\
\hline Dan Dezarov & Elysium Inc. \\
\hline Rick Eckenrode & RECON Services \\
\hline Katie Farris & Newport News Shipbuilding \\
\hline Lyle Fischer & CAPVIDIA \\
\hline Denise Fitzgerald & MIT Lincoln Laboratory \\
\hline Bob Goosen & Purdue MEP \\
\hline Andrew Hall & Rolls Royce \\
\hline Greg Harris & U.S. Army/DMDII \\
\hline Thomas Hedberg & NIST \\
\hline Don Hemmelgarn & ITI \\
\hline Jennifer Herron & Action Engineering \\
\hline Anthony Holden & U.S. Army \\
\hline Paul Huang & NIST/ONR \\
\hline Hui-Min Huang & NIST \\
\hline Lorenzo Landin & Boeing \\
\hline Ben Kassel & U.S. Navy \\
\hline Kong Ma & Rolls Royce \\
\hline Larry Maggiano & Mitutoyo America \\
\hline Adrian Miura & Sandia National Laboratories \\
\hline Ram Pentakota & Johnson Controls \\
\hline Gene Peppe & Naval Air Warfare Center \\
\hline Jason Presler & Rockwell Collins \\
\hline Michael Shaw & Rolls Royce Corp. \\
\hline Atsuto Soma & Elysium Co. Ltd. \\
\hline Genevieve Teel & U.S. Army/IRTC \\
\hline Phil Teuscher & NAWC WD China Lake \\
\hline Denise Welch & Honeywell FM\&T \\
\hline Mike Werkheiser & PRATT \& Whitney \\
\hline Roy Whittenburg & Newport News Shipbuilding \\
\hline Brent Woodhouse & \\
\hline
\end{tabular}




\section{Acronyms}

\begin{tabular}{|l|l|}
\hline Acronym & Definition \\
\hline 3D & Three Dimensional \\
\hline BoC & Bill of Characteristics \\
\hline CAD & Computer-Aided Design \\
\hline CAO & Conception Assistée par Ordinateur (French: Computer-Aided Design) \\
\hline CM & Change Management \\
\hline COP & Conference of Parties \\
\hline DM & Data Management \\
\hline DoD & Department of Defense \\
\hline FAA & Federal Aviation Administration \\
\hline LoTAR & Long-term archival and retrieval \\
\hline MBD & Model-Based Definition \\
\hline MBE & Model-Based Enterprise \\
\hline NIST & National Institute of Standards and Technology \\
\hline OMG & Object Management Group \\
\hline PDF & Portable Document Format \\
\hline PDM & Product Data Management \\
\hline PLM & Product Lifecycle Management \\
\hline PMI & Product and Manufacturing Information \\
\hline QIF & Quality Information Framework \\
\hline R\&D & Research and Development \\
\hline ROI & Return on Investment \\
\hline SME & Subject Matter Expert \\
\hline SysML & Systems Modeling Language \\
\hline UL & Underwriters Laboratories \\
\hline Wiki & A website that allows collaborative editing \\
\hline XMI & XML Metadata Interchange \\
\hline
\end{tabular}




\section{References}

Hedberg Jr, T. D., Lubell, J., Fischer, L., Maggiano, L., \& Barnard Feeney, A. (2016, June). Testing the Digital Thread in Support of Model-Based Manufacturing and Inspection. Journal of Computing and Information Science in Engineering, 16(2), 1-10.

Model Based Enterprise. (2014). Retrieved from Model Based Enterprise: http://model-basedenterprise.org/model-based-enterprise.html 